\title{
Концепции биоморфизма и параметризма в современной архитектуре: проблемы и перспективы
}

\author{
И.А.Добрицына, НИИТИАГ, Москва
}

В статье рассмотрены новейшие явления в архитектуре, вызванные возможностями новой цифровой технологии. 0собое внимание уделено концепции «параметризма», предложенной германо-британским философом Патриком Шумахером (архитектурное бюро «Заха Хадид Арчитектс»). Показано, что Шумахер предлагает экономически выгодный и сверхбыстрый в исполнении принцип проектирования для сферы массовой городской застройки, основанный на математике «параметризма» и позволяющий массовое продуцирование вариаций архитектурной формы в пределах программы.

Кратко оценена книга Шумахера «Автопоэзис архитектуры», которая несёт пафос прагматики, построена на матрице теории систем и одновременно - на теории коммуникации социолога Никласа Лумана, рассматривающего социальные системы по аналогии с системами биологическими. Термин «автопойезис», означающий самовоспроизводство, заимствован Луманом у нейробиологов. Социальная система, по мнению социолога, аналогична биологической и способна производить и воспроизводить все свои части из себя самой. Показано, что - в свою очередь - термин «аутопойезис» заимствован у социолога Лумана философом Патриком Шумахером в теоретической работе «Автопоэзис архитектуры». Подчеркивается, что размышления Шумахера соответственно предстают: во-первых, в коммуникативной и, во-вторых, в биологической логике. И тем самым уходят от формально-пространственной логики архитектурной профессии, построенной сегодня на цифровом основании, устремляясь к прагматике экономики пост-фордизма.

Автор настоящей статьи рассматривает данную концепцию критически, поскольку заявленный принцип противоречит онтологическому началу человеческого поселения, превращая городскую застройку из «города для людей» в сотообразное «подобие подобий».

В критике автор статьи опирается на собственные доводы и на концепции теоретиков архитектуры: американца Кристофера Хайта, британца Марио Карпо, голландца Нильса Прака.

Ключевые слова: параметризм, биоморфизм, природоподобие, цифровая технология, вариабельные параметры, постфордизм, Патрик Шумахер, биополитические интенции в архитектуре, антропоморфизм как контрпозиция, Кристофер Хайт, Нильс Прак. Марк Фостер Гейг
The Concepts of Biomorphism and Parametrism in Modern Architecture: Problems and Prospects

I.A.Dobritsyna, NIITIAG, Moscow

The article deals with the latest phenomena in architecture caused by the possibilities of the new digital technology. Special attention is paid to the concept of "parametrism", proposed by the German-British philosopher Patrick Schumacher (Bureau"Zaha Hadid Architects"). It is shown that Schumacher offers a cost-effective and ultra-fast design principle for the sphere of mass urban development, based on the mathematics of "parametrism" and allowing the mass production of variations of architectural forms within the program.

Schumacher's book "Autopoiesis of architecture", which carries the pathos of pragmatics, is based on the matrix of the theory of systems and at the same time - on the theory of communication of sociologist Niklas Luhmann, who considers social systems by analogy with biological systems, is briefly evaluated. The term "autopoiesis," meaning selfreplication, was borrowed by Luhmann from neuroscientists. The social system, according to the sociologist, is analogous to the biological one and is capable of producing and reproducing all its parts from itself. It is shown that - in turn - the term autopoiesis is borrowed from the sociologist Luhmann philosopher Patrick Schumacher in the theoretical work "Autopoiesis of architecture". It is emphasized that Schumacher's reflections appear accordingly: first, in communicative and second, in biologicallogic. And thus moving away from the formal-spatial logic of the architectural profession, built today on a digital basis, striving for the pragmatics of the economy of post-Fordism.

The author of this article examines this concept is critical because the alleged principle is contrary to the ontological beginning of human settlements, transforming the urban development of "cities for people" honeycombed "likelikes".

In criticism, the author relies on his own arguments and on the concepts of theorists of architecture: American Christopher Hite, British Mario Carpo, Dutch Niels Prak.

Keywords: digital technology, parametrism, biomorphism, nature similarity, variable parameters, post-Fordism, Patrick Schumacher, biopolitical intentions in architecture, anthropomorphism as a counterposition, Christopher Hight, Niels Prak, Mario Carpo, Mark Foster Gage. 


\section{Проблемное поле архитектурного биоморфизма} и параметризма

Природоподобие в архитектурной форме стало возможно с приходом новой технологии, вызвавшей поначалу неподдельный интерес архитекторов. Но, по мере совершенствования технологий, на второй волне цифровой архитектуры этот тренд стал вызывать и тревогу.

Автор использует термин «биоморфизм»в широком смысле - для определения экспериментов с формой, вызывающей ассоциации с живой природой. Близок к термину «биоморфизм» ещё один термин - «геоморфизм».

Известно, что 1990-е годы были особым переходным периодом в истории архитектурного формообразования, который можно назвать критической точкой. Архитектурное воображение было развёрнуто к свободно растущим в цифровом проектном процессе природоподобным формам. Термин «лэндформная архитектура» возник ещё в 1990-е на подъёме так называемой нелинейной архитектуры. Особенно известной была линия от бионики к нелинейной архитектуре, или, как называл цифровую архитектуру в 1990-е Чарлз Дженкс, - клэндформной архитектуре [1]. Формальная родственность с природными формами алгоритмизированного продукта была визуально очевидна. Начальные опыты не выходили за пределы единичного объекта, но постепенно вышли и на градостроительный уровень.

К началу XXI века эта тенденция, усиленная развитым компьютерным моделированием, уже имела историю. И об этом немало уже написано.

B XXI веке «нелинейные» опыты, благодаря исключительно продвижению технологии, переросли, во-первых, в экспериментальную (и потому малоизвестную) биологическую тенденцию, во-вторых, в широко известную и вызывающую споры параметрическую тенденцию.

С одной стороны, в настоящее время концепция природоподобия или биоморфизма, особенно интенсивно и даже напористо манифестируется. Так, известно, что достигла пика манифестация параметризма, едва ли не как стиля новой эпохи. С другой стороны, в первом же десятилетии XXI века возникла и иная волна, разворачивающая архитектуру снова к антропоморфизму, отказ от которого, как представляется автору, в принципе невозможен: так как сама природа человека (не технология, не социология, а именно природа человека) требует особой пространственной организации, благоприятной для его существования. Но как понимается природа человека? Отметим сразу же, что жёстких критериев здесь нет.

Таким образом, сегодня есть основания полагать, что рождается ситуация противостояния - природоподобной, но жёстко технологизированной архитектуры, с одной стороны, и архитектуры, удерживающей принципиальные основания природы человека. Противостояние рождает сложнейшую проблему, требующую исследования. Рассмотрим, как далеко зашло это противостояние.

\section{Радикальный биомиметизм}

Радикализм является едва ли не преобладающим настроением в различных экспериментальных группах и крупных бюро, обращённых к теме биоморфизма. Так, современный испанский исследователь Алберто Эстевец из Барселоны возглавляет лабораторию «Биоцифровая архитектура и генетика». Он считает, что сочетание новейших биологических и цифровых технологий открывает новые возможности и преимущества для производства (именно производства!) новой архитектуры: тем более что биологи обнаруживают сегодня все больший потенциал форм в природном мире [2].

Барселонская группа работает с ДНК, как если бы это была генетическая «природная программа». Точнее сказать, что группа работает с программным обеспечением в архитектуре так, как если бы оно было «цифровым вариантом ДНК». Таким образом, область интересов барселонской группы - биоцифровая архитектура, понимаемая как своеобразное смешение генетики и кибернетики. Работа началась с момента, когда новая биологическая и новая цифровая технологии создали условия для нового подхода к проектированию. Даже беглое знакомство с работами мастерской доказывает, что сфера интереса здесь в настоящее время не выходит за пределы формы совсем несложных так называемых малых форм архитектуры.

\section{Манифестация параметризма. Бюро «Хадид Архитек- тура» и Патрик Шумахер}

Теоретическая схема

Манифест параметризма философа Патрика Шумахера был предъявлен в двухтомнике «Автопоэзис архитектуры» [3].

Книга «Автопоэзис архитектуры»- это теория Шумахера. Автопоэзис - означает самопостроение, самовоспроизводство. Автор подчёркивает намерение породить и саму теорию как бы изнутри профессии.

Шумахер манифестирует параметризм не больше и не меньше как формулу «эпохального стиля». Характерно, что само понятие стиль в данном случае меняется. Стиль декларируется Шумахером не столько как общность визуальных и структурных компонентов формы в искусстве эпохи (согласно Винкельману) и даже не как мировоззренческий критерий человеческого начала (согласно Франклу), но прежде всего как система установок для проектирования (причём, цифрового проектирования) и одновременно - как система, учитывающая характерную для нашего времени быструю постоянную смену ценностей и приоритетов самой культуры.

Сегодня понятно, что природа явлений со временем меняется; не исключено, что реально потребуется как минимум «расширение» самой категории «стиль» ради создания гибкой системы понятий, описывающих в чём-то подобное современное явление.

Исторически именно философия, как правило, была, да и есть, средоточием изменений, где собираются наиболее подвижные модели коммуникации: здесь они очерчиваются 
совместно и отвлечённо, систематизированно. Но затем они рассеиваются обратно в различные специализированные дискурсы, которые, в свою очередь, могут стать компетентными, чтобы инкорпорировать, слить воедино новое продвижение теории уже внутри данных дискурсов.

Все это делает философию до сих пор употребимым ресурсом для архитектурного теоретизирования. Понятно, что никто не станет принуждать архитектора читать современную философию, но обращение к философии можно ожидать от тех мыслителей, которые имеют амбицию развивать архитектурную теорию и продвигать общий уровень сложности в сфере архитектурной коммуникации. Безусловно, такие работы теоретиков архитектуры, информированных философами, никогда не были вкладом в саму философию; они оставались адресованными исключительно архитектору. Иначе говоря, такого рода коммуникации всегда расположены внутри самой архитектуры, даже если их исток лежит где-то снаружи.

Теория архитектурного автопоэзиса также вытягивает свои ключевые теоретические ресурсы снаружи дисциплины, в то время как сам предмет её весьма амбициозного замысла лежит целиком внутри архитектурной дисциплины.

Если теоретики архитектуры «импортируют» новые схемы мышления и разворачивают в свою сторону те аргументы, которые могут стать продуктивным ресурсом внутри архитектуры, то тем самым они могут весьма удачно открывать свои собственные источники и к тому же задавать простор начальному тезису.

\section{Никлас Луман и прагматика}

Но книга Шумахера также несёт пафос прагматики, она построена на матрице теории систем и одновременно - на социальной теории коммуникации Никласа Лумана (1922-1998), всемирно известного социолога, автора оригинальных разработок по теории социальных систем, теориям правового государства, экономике общества, социологии риска, общественному праву.

Луман рассматривает социальные системы по аналогии с биологическими системами. Из биологии, точнее у нейробиологов, заимствован термин «аутопойезис», означающий самовоспроизводство. Социальная система, по мнению Лумана, аналогична биологической и способна производить и воспроизводить все свои части из себя самой.

«Автопоэзис» - стал ведущим термином философа Патрика Шумахера. Нам важно оценить позицию Шумахера по отношению к философии, науке, собственно к архитектуре, с одной стороны, и к цифровому проектированию, с другой. Коротко проследим обоснование его теории саморазвития (или автопоэзиса) архитектуры.

Шумахер предполагает, что собственно феномен архитектуры может быть адекватно «схвачен», если он анализируется как некая автономная сеть коммуникации (как автопоэтическая система коммуникации). Его теория архитектурного автопоэзиса - это некая общая теория архитектуры, которая адресована самой себе - то есть исключительно дисциплине «архитектура». Она фокусирует архитектурные коммуникации и то как они зависят от внешней среды, она рождает некие новые коммуникационные структуры.

Теория в данном случае не есть прямая рефлексия на некий наблюдаемый порядок мира. Напротив, это скорее сконструированный инструментарий, чтобы задать некий ощутимый - хоть и временный - порядок тем феноменам, которые мы сегодня переживаем, испытываем, претерпеваем.

И потому теория архитектурного автопоэзиса Шумахера притягивает к себе теорию систем второго порядка. Будучи сам философом, он концентрируется на идеях названного выше философа и специалиста по социальной теории Никласа Лумана. Социальная теория систем Лумана предлагает широкую теорию современного общества на основе общей теории социальных систем, истолкованных им как системы коммуникации.

Понятно, что такое узкое истолкование архитектуры исключительно как системы коммуникаций - позволяет развить теорию архитектуры внутри весьма широкого, я бы сказала, расплывчатого, теоретического контекста. Но всё же, обращаясь к истории архитектуры, наверное, стоит вспомнить, что наиболее амбициозные архитектурные теоретики - такие как Альберти, а много позже Земпер, Корбюзье или Кулхаас - всегда понимали, что архитектура обязана строить теорию самостоятельно и при этом теоретизировать как бы изнутри некоей условной теории общества. Иначе говоря, очередной рывок развития общества теоретически должен быть «схвачен»в его сложной исторической траектории, чтобы уловить некое тождество в подходе к социальным задачам грядущего и одновременно удержать релевантность, то есть степень соответствия, но уже с точки зрения самой архитектуры.

Теория архитектурного автопоэзиса выстраивает внушительную панораму системы коммуникаций для стратегической экскурсии за пределы горизонта самого архитектурного мышления. Цель такого рода экскурсии - получить путеводную нить к потенциальной концептуализации архитектуры.

Исходя из аналитики Лумана, архитектура должна выйти на коммуникативные стратегии иных дискурсов.

Такого рода стратегия как будто должна продвинуть архитектуру. Однако, она скорее всего ведёт к размыванию дисциплинарных границ архитектуры.

Стартовая позиция Лумана - это решение анализировать само общество в терминах хорошо продифференцированных (то есть чётко различающихся) систем коммуникации. Он характеризует каждую систему коммуникации как автопоэтическую систему.

Луман пишет: «Система коммуникации это... полностью закрытая система, генерирующая компоненты, из которых она состоит, через коммуникацию самой себя. И именно в этом смысле система коммуникации есть автопоэтическая 
система, которая продуцирует и репродуцирует через систему всё то, что работает ради системы как единого целого... Система коммуникации, сама по себе точно определяется не только своими собственными элементами - в каждом случае есть единица коммуникации, которая не может далее быть разделена, поскольку имеет свою структуру» [4, с. 160-161].

Система коммуникации таким образом фиксирует некие границы «стиля». Очевидно, по Луману, не столько формальное основание, сколько социально-коммуникативное должно удерживать некое направление в архитектуре. После знакомства с рассуждением Лумана размышления Шумахера предстают в этой коммуникативной логике. Его основные тезисы звучат примерно так: 1) все авангардные стили являются проектно-исследовательскими программами. Они начинаются как прогрессивные исследовательские программы, созревают как продуктивные символы веры (догмы) и завершаются как вырождающиеся догмы; 2) эстетические ценности заключены в капсулу конденсированного группового опыта с полезными символами веры. Их инертность означает что их развитие скорее революционно, чем эволюционно; 3) архитектура зависит от своего посредника - рисованой или цифровой модели. И потому необходимо поддерживать прогресс проектирования, но защищать проектировщика от излишней уступчивости современной технологии.

Звучит весьма убедительно. Но рассмотрим явление подробней.

Наступательный радикализм Патрика Шумахера. Параметризм манифестируется как стиль

Как известно сам термин «параметризм» происходит от концепта «параметрическое проектирование». Имеется в виду проектный процесс, который использует вариабельные параметры (или вариабельные алгоритмы), чтобы создавать новую мягко пластическую природоподобную геометрию среды и новые объекты.

И до поры параметрическое проектирование представлялось лишь способом отрицания предшествующей методологии и эстетики. Но сегодня - с добавлением суффикса -изм параметризм претендует на все - и стилистические, и социальные, и экономические - интенции в продвижении архитектуры. Более того, параметризм выходит в город, в городскую среду не как аффектирующая постройка в духе Хадид, а как принцип застройки города нашего времени.

Рассмотрим рассуждения Шумахера. Шумахер считает, что параметризм как стиль, причём стиль эпохальный, как бы родился из цифровых методов анимации. Его последние разработки основаны на передовых параметрических проектных системах и скриптовых методах. Стиль, как заявлено автором, разработан за последние 15 лет и теперь требует гегемонии. Параметризм как стиль следует за модернизмом как волна систематических инноваций. Стиль закрывает наконец переходный период неуверенности, порождённой кризисом модернизма... Шумахер подчёркивает, что необходимо определиться, в чём сегодня заключается общественная функция архитектуры и градостроения.

Он считает, что в первую очередь - это упорядочение социальных процессов, что «поздние архитекторы-модернисты использовали параметрические инструменты ради обслуживания эстетики самого модернизма, маскируя надвигающуюся сложность».

А вот «современная параметристская чувствительность движется в противоположном направлении, она стремится к максимальным акцентам, к визуальному преувеличению, к дифференцирующей логике. Эстетически параметризм это элегантность текучести без шва, родственная естественным природным системам, что и является важнейшим внешним признаком параметризма» [5].

Итак, после вчитывания в тезисы становится очевидным подтекст сентенций параметризма, интерес автора трактата к гибкому и ускоренному управлению динамически развивающейся структурой города. Отмечалось и прежде: «Шумахер основывает свою концепцию на новейших представлениях науки (на теории самоорганизации), одновременно на представлениях социологии, экономики (концепция постфордизма), втягивает проблемы экологии, учитывает так называемую дромологию (скорость перемен, по Вирилио), но при этом главным мотором мышления видит технологию - новейшую компьютерную параметрическую технологию проектирования. И весьма парадоксально, что в программе формального языка он не выходит за рамки искусства Хадид, что придаёт его манифесту весьма специфический оттенок» [6] (рис.).

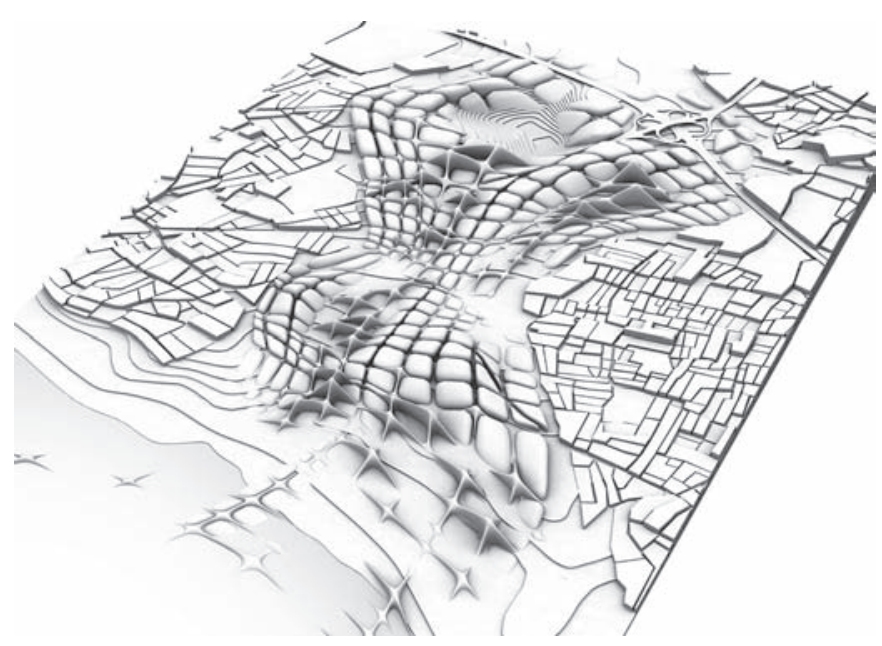

Картал-Пендик. Мастер-план. Проект. Архитектурное бюро «Заха Хадид Арчитектс». Турция. 2006 год: глобальная компьютерная модель «Мауа», показывающая внутреннюю артикуляцию города между условными «башнями» по центральной линии и периметральными блоками, масштабно сопоставимыми с окружающей тканью исторической застройки (источник: https://i.pinimg.com/originals/18/11) e7/1811e7345c16f41fce1770e5a063dd44.jpg) 


\section{Критика параметризма Шумахера}

Марк Фостер Гейдж

По мнению декана Йельской школы Марка Фостера Гейджа, Шумахеровский параметризм «не является ни стилем, ни движением, но попросту проявлением вездесущей технологии XXI века в сочетании со стилистическим предпочтением топологически производных (гладких) цифровых поверхностей» $[7$, p. 130]

«Параметрический проект Шумахера, 28 лет спустя (после Делёза), является, пожалуй, одновременно и величайшим достижением, но и последним выплеском сильного делезианского влияния в архитектурном дискурсе. Возможно, сегодня пришло время выйти за рамки всего сложенного, расплывчатого, кочевого, плавно дифференцированного и постоянно сохраняющегося состояния становления, но никогда не устойчивости» [7, p. 132].

Гейдж опирается на философа Грэхэма Хармана, выступая против идеи лингвистического поворота, скрытой в декларативном пафосе Шумахера, возвещающем приход параметризма как нового стиля в архитектуре. Благодаря своей всё более влиятельной философской концепции «объектно-ориентированной онтологии», Харман предлагает смелый вызов любому повороту, претендующему на глобальный «языковый поворот». Тем самым Харман предлагает вызов всей идеалистической (идеологической) основе западной философии, доминирующей ещё со времён Просвещения.

\section{Mapuo Kapno}

Профессор теории и истории архитектуры в Бартлетт-Скул Марио Карпо справедливо видит в тактике Шумахера чёткий прагматический поворот архитектуры. В чём же конкретно он проявился? Прагматическое направление мысли - не столько высокая теория, сколько дискурс о проектировании. Важно - что именно привлекается для обсуждения, что истолковывается в этом прагматическом дискурсе как предмет осмысления и проектирования. Прагматический поворот не исключает идеологизацию и мифологизацию представлений профессионала, но заметно усиливает социально-экономические мотивы, а также биополитические интенции самой архитектуры как властной социальной структуры.

Марио Карпо в своей книге «Цифровой поворот в архитектуре» [8] подчёркивает, что Патрик Шумахер из бюро «Заха Хадид арчитектс» определяет параметризм как «устойчивую новую господствующую парадигму», рождённую постиндустриальным обществом и ему соответствующую. Параметризм ориентирован на постфордизм. А постфордизм основан на принципе кастомизации (изготовлении массовой продукции, но под заказ) и на принципе сложности, в то время как индустриальная эпоха, будучи основанной на стандартизации, не забывала эффектов формы и масштаба.

Математика параметризма, поддержанная сегодня электронной компьютеризацией, является наилучшим средством для регулирования вариаций и, следовательно, для массового продуцирования вариаций. Мгновенная вариативность проекта облегчает контакт с заказчиком.

Становится всё более очевидным, что параметризм ставит цель полного авторитарного контроля проекта во всех масштабах - от дома до города. Параметризм делает ставку на технологию, экономику и социологию. Однако понятно, что контрпозиция не может не возникнуть.

\section{Антропоморфизм как контрпозиция}

Мы предлагаем здесь оценить концепцию Кристофера Хайта, известного американского теоретика архитектуры, как контрпозицию концепции параметризма. Кристофер Хайт в монографии 2007 года «Принципы архитектуры в век кибернетики» утверждал: «Поскольку цифровая (а сегодня ещё и биологическая) технологии вызывают экзистенциальную тревогу, тема человеческого тела снова становится центральной. Мы наблюдаем попытку архитектора сосредоточить внимание на субъективности восприятия и одновременно на достоверной переоценке связи человек-природа-архитектура в меняющихся “постгуманных" условиях» [9, р. 6].

В своей работе Хайт исследует - каким образом проблемы тела человека и проблемы существования человека учитываются в самой центральной части архитектурного дискурса последних десятилетий. Это особенно актуально на фоне недавних попыток попросту переформулировать отношение архитектуры к гуманизму, к современности, к новой технологии. Хайт ставит под сомнение ряд концепций и категорий архитектурной истории и одновременно ряд концепций современных дебатов, помещая оба ряда в более широкий культурный и технологический контекст.

Хайт поясняет своё пристальное внимание к категории «тела» в архитектурной теории. Миру предъявлена угроза общетехнологических перемен. И потому необходимо найти резерв противостояния чрезмерной технологизации архитектурного проекта и чрезмерной технологизации самого человека и его среды обитания.

«Мифы виртуальной реальности и сетевой информационной технологии предвещают решительное ослабление любых чётко ограниченных целостностей и замещение их электронными потоками. Присутствие тела человека и стабильность этого присутствия как модели игнорируется и замещается размножающимися симулякрами... Моя главная позиция исследования родилась из интереса к весьма неожиданному, и прежде необъяснимому, но повторяющемуся появлению человеческой фигуры в архитектурном дискурсе примерно с середины двадцатого столетия. Моя позиция родилась из интереса к этому явлению как факту, а также из интереса к совсем недавнему движению самой архитектурной аналитики - в область телесных метафор и подобных отсылок. И все это проявилось на фоне обсуждения ценностей постгуманизма, цифровой технологии, глобализации и новой науки» [9, p. 6-7]

Хайт предлагает и исследует специфический тезис - идею восхождения в философском сознании некоего промежу- 
точного тела, и предлагает её в трёх форматах: 1) в формате теоретической дефиниции, 2) в формате мысленного и условного растягивания естественных границ человеческого тела в условиях его технологической интеграции, а также - 3) в формате тела саморазвивающегося, понимаемого сегодня как предтеча тела кибернетического.

Хайт преподносит эту по сути уже кибернетическую модель совсем не как новость и даже не как только ещё возникающую человеческую форму, но как некий «техно-социальный гибрид», который в силу самих обстоятельств уже возник где-то в середине XX столетия.

\section{Нильс Прак: опора на гештальт}

Ещё совсем недавно, в 1966 году, голландский архитектор и теоретик Нильс Прак отмечал, что благодаря симметричности наших тел... и «встроенной в нас картезианской по сути системе координат, мы ориентируемся в мире» [10, с. 53].

При этом «концептуальное пространство» как некий образ пространства возникает в процессе освоения архитектурного пространства. Это «концептуальное пространство» - производное от нашего умственного склада и подчиняется гештальтным законам восприятия.

И потому ради утверждения человека в своей среде обитания ему необходима психологическая опора на присутствие в ней так называемых филебовых тел (термин, производный от платоновых тел) - куб, сфера и т.д.

Однако филебовы тела - более тонкое понятие, родившееся из законов гештальта, они составляют контраст формам природы, но не обязательно ограничены правилом прямого угла.

Прак напомнил об этом человечеству и, в первую очередь, архитекторам, миссия которых - отвечать за жизненную устроенность человека. Напомнил в 1960-е годы, когда призрак киберчеловека ещё не возникал.

\section{Заключение}

Прихожу к выводу, что, с одной стороны, современному архитектору нельзя оставаться «супер-специализированным проектировщиком формы», с другой - нельзя становиться «менеджером внешних по отношению к архитектуре сил». Требуется взвешенное отношение к сложившейся ситуации. Пластика архитектурных объектов Захи Хадид принимает принципы параметризма. Градостроительные задачи требуют иного подхода.

Если говорить об онтологической стороне вопроса, то со своей стороны, я убеждена, что погружение человека в городскую среду, построенную на основании одной лишь неевклидовой геометрии, - более чем негуманно. Пространственная ориентация затруднена - а значит жизненная обустроенность неупорядочена. Возникающая в этом случае физическая дезинтеграция способствует и социальной дезинтеграции. Как мы понимаем, концепция параметризма, заложенная в проект, становится средством затягивания человека в онтологически чуждую среду. Просторы параметрики лишают человека визуальных ориентиров и снижают феноменологическую чёткость городского пейзажа.

И потому затронутая здесь проблема сегодня только обостряется и требует исследования.

\section{Литература}

1. Jencks, Charles. Landform Architecture. Emergent in the Nineties // Architectural Design. - 1997. - V.67. - № 9-10.

2. Estévez, Alberto T. Biodigital Architecture // Computation: The new realm of architectural design / Ed. ECAADe. - Istanbul, 2009. - P. 681-686.

3. Schumacher, Patrik. The autopoiesis of Architecture: A New Framework for Architecture. - London : A John Wiley and Sons, Ltd. Publication. - Vol 1, 2013; Vol. 2, 2014

4. Luhmann, Niklas. Theories of Distinction. - Stanford : Stanford University Press, 2002.

5. Schumacher, Patrik. Параметризм - Parametricism: 6 articles by Patrik Schumacher [Электронный ресурс] / Translated into Russian Language by Pavel Beliy // Digital Cities AD (Architectural Design). Вып. 79.- 2009. - № 4 - Режим доступа: http://www.patrikschumacher.com/Texts/Parametricism_ Russian\%20text.html (дата обращения 12.06.2019).

6. Добрицына, И.А. Между феноменологией и прагматикой. К проблеме интерпретации главных тем теории цифровой архитектуры // Современная архитектура мира. Вып. 5 / отв. ред. Н.А. Коновалова. - М-СПб : Нестор-История, 2015. - 328 с.

7. Gage, Mark Foster. A Hospice for Parametricism // Digital Cities AD (Architectural Design). - 2016. - № 6. -P. 128-133.

8. Carpo, Mario. The Digital Turn in Architecture 1992-2012. - London : Wiley, 2013.

9. Hight, Christopher. Architectural Principles in the age of Cybernetics. -N-Y : Kindle Edition, 2007.

10. Прак, Нильс Лунинг. Язык архитектуры. Очерки архитектурной теории / пер. с англ. Е. Ванеян; под науч. ред. С. Ванеяна; РАНХиГС - М. : Дело , 2017. - 288 с. ISBN 978-57749-1189-9.

11. Maturana, Humberto and Varela, Francisco. Autopoiesis and Cognition - the Realization of the Living. - Dordrecht : Reidel Publishing Company, 1980. - 171 p.

\section{References}

1. Jencks Charles. Landform Architecture. Emergent in the Nineties. Architectural Design. 1997, Vol. 67, no. № 9/10. (In Engl.)

2. Estévez Alberto T. Biodigital Architecture. Computation: the new realm of architectural design, Ed. ECAADe. Istanbul, 2009, pp. 681-686. (In Engl.)

3. Schumacher Patrik. The autopoiesis of Architecture: a New Framework for Architecture. London, A John Wiley and Sons, Ltd. Publication, Vol 1, 2013; Vol. 2, 2014. (In Engl.)

4. Luhmann Niklas. Theories of Distinction. Stanford, Stanford University Press, 2002. 
5. Schumacher, Patrik. Parametricism: 6 articles by Patrik Schumacher. London, 2008 [Elektronnyi resurs]. Digital Cities AD (Architectural Design), 2009, Iss. 79, no. 4. URL: http://www. patrikschumacher.com/Texts/Parametricism_Russian\%20text. html (Accessed 12.06.2019) (In Engl.)

6. Dobritsyna I.A. Mezhdu fenomenologiei i pragmatikoi. $\mathrm{K}$ probleme interpretatsii glavnykh tem teorii tsifrovoi arkhitektury [Between phenomenology and pragmatics. To the problem of interpretation of the main topics of the theory of digital architecture]. In N.A. Konovalova (ed.) Sovremennaya arkhitektura mira [Modern world architecture], Iss. 5. MoscowSaint Petersburg, Nestor-Istoriya Publ., 2015, 328 p. (In Russ., abstr. in Engl.)
7. Gage Mark Foster. A Hospice for Parametricism. Digital Cities AD (Architectural Design), 2016, no. 6, pp. 128-133. (In Engl.)

8. Carpo Mario. The Digital Turn in Architecture 1992-2012. London, Wiley, 2013.

9. Hight Christopher. Architectural Principles in the Age of Cybernetics. New-York, Kindle Edition, 2007. (In Engl.)

10. Prak Nil's Luning. Yazyk arkhitektury. Ocherki arkhitekturnoi teorii [The language of architecture. Essays on architectural theory]. S. Vaneyan (ed.). Moscow, Delo Publ., 2017, 288 p., ISBN 978-5-7749-1189-9. (In Russ.)

11. Maturana Humberto, Varela Francisco. Autopoiesis and Cognition - The Realization of the Living. Dordrecht, Reidel Publishing Company, 1980, 171 p. (In Engl.)

Добрицына Ирина Александровна (Москва). Доктор архитектуры, советник РААСН. Заведующая отделом проблем теории архитектуры и главный научный сотрудник Научно-исследовательского института теории и истории архитектуры и градостроительства (филиал ФГБУ «ЦНИИП Минстроя России») (111024, Москва, ул. Душинская, 9. НИИТИАГ). Эл. почта: rinadobrits@ mail.ru.

Dobritsyna Irina Aleksandrovna (Москва).Doctor of Architecture, Advisor of RAACS, Chief Researcher and Head of the Department of problems of the theory of architecture at the Research Institute of Theory and History of Architecture and Urban Planning (9 Dushinskaya st., Moscow, 111024. NIITIAG), branch of the Central Institute for Research and Design of the Ministry of Construction and Housing and Communal Services of the Russian Federation (TsNIIP Minstroy of Russia).E-mail: rinadobrits@mail.ru 